\title{
The Impact of Information Technology on Energy Consumption and Carbon Emissions
}

\author{
by Erol Gelenbe and Yves Caseau
}

\section{Editor's Introduction}

In this article the authors evaluate the impact of different sectors of information and communication technologies (ICT) on energy consumption and $\mathrm{CO}_{2}$ emissions. ICT is understood to cover computer and peripheral equipment including local area networks, telecommunication equipment and networks, and data centers. In 2012, close to 4.7 percent of the world's electrical energy was consumed by ICT, releasing into the atmosphere roughly 1.7 percent of the total $\mathrm{CO}_{2}$ emissions. These numbers are growing, although the improving energy efficiency of ICT equipment leads to a slower growth of these metrics than the increase of ICT's usage worldwide. On the other hand, ICT can contribute to a reduction in energy consumption and $\mathrm{CO}_{2}$ impact in other sectors, such as transportation, smart buildings and virtual work and learning. Regarding transportation, studies show in the United States the average number of miles traveled in private vehicles has decreased significantly since 2007 despite a sustained growth over many decades; the drop has persisted after the end of the most recent economic crisis, suggesting that these energy savings may be attributed to changes in the modes of work and commerce induced by ICT. 


\title{
The Impact of Information Technology on Energy Consumption and Carbon Emissions
}

\author{
by Erol Gelenbe and Yves Caseau
}

The footprint of ICT (information and communication technologies) is growing continuously in our lives, in an increasing number of countries. A vivid illustration is the increase in the number of mobile phones in the world (more than 6 billion in 2013), and the increasing use of ICT in sensors and cyber-physical systems that help improve our security and wellbeing $[1,2,3,4]$. Approximately 10 years ago, we began to hear expressions of fear that ICT would come to eat an unsustainable part of the overall available energy. Addressing this is important, this paper discusses the fraction of energy consumption that is related to the world's increasing usage of ICT and suggests directions for research. The use of ICT to manage electrical energy is discussed elsewhere [5]. However, we see no evidence that the ICT footprint is likely to grow unsustainably large.

Note that usage does not cover the manufacturing of computer equipment. This is consistent with other comparisons in the rest of the paper. For instance, when we discuss the energy consumed by individual automobiles in the U.S. we do not include the energy consumed by the manufacturing of cars, nor do we include the energy consumed to build and maintain roads and highways (which is actually very high). On the other hand, standard maintenance procedures for ICT equipment are included in our evaluation of energy consumption.

Also the term "ICT" does not include equipment such as TVs or sound systems used for entertainment, which are all becoming increasingly digital and connected to the Internet. ICT is understood here to cover computer and peripheral equipment including local area networks, telecommunication equipment (such as routers and switches) and networks including base stations, and data centers. Although we do not consider TV or sound technology, our analysis does include energy consumption due to multimedia content being carried over the Internet and over the mobile operator backbone networks. Multimedia content is difficult to distinguish from other packet, voice, or video traffic in networks.

In 2012, ICT usage consumed 4.7 percent of electricity worldwide [6, 7], amounting to approximately 920 TWh (1 TWh is a terawatt-hour or $10^{12}$ watt-hours). While overall worldwide electricity consumption (around 19,000 TWh) is 15 percent of the total energy that is being produced (around 150,000 TWh), using the International Energy Agency as a source [8]. The main point of this article is, although ICT usage is bound to grow at a quick pace during the next 10 years, the associated electricity consumption should grow much more moderately. ICT's 
usage growth, which depends on the number of connected ICT devices, will be offset by an efficiency increase. Since ICT plays a significant role in increasing the energy efficiency of a large number of activities, it follows that the overall balance should be positive, and ICT will help us save much more energy than it requires for its own use.

\section{Early and More Recent Predictions}

According to a Gartner Group report from 2007 [9], the total energy consumption related to ICT was expected to grow at an alarming rate, and its carbon footprint would become comparable to that of airline transportation-at approximately 2 percent of the total emissions of carbon dioxide $\left(\mathrm{CO}_{2}\right)$. The 2020 forecast based on this predicted trend was that the share of the $\mathrm{CO}_{2}$ footprint of data centers was expected to become smaller over the years (18 percent), compared with telecommunications ( 25 percent) and ICT devices ( 57 percent). If we assume an average value of $400 \mathrm{~g}$ of $\mathrm{CO}_{2}$ emissions [10] for each electricity kWh (Europe's average is $370 \mathrm{~g}$, whereas it is a third of this value for France due to the importance of nuclear assets), the $\mathrm{CO}_{2}$ emissions that were predicted in 2007 by this Gartner Group report is equivalent to a total electricity consumption of $3270 \mathrm{TWh}$.

From that early prediction one might then logically conclude ICT would consume an increasing share of the electricity worldwide in the coming decades, driven by the economic and cultural development of the BRIC countries and Asia, Africa, and Latin America. The question that was asked at the time was whether the benefits of ICT in other industrial sectors would offset this increase.

The Gartner Group, focusing more particularly on India, also reported [9] the electricity consumption due to ICT usage within Indian enterprises would rise from 24 TWh in 2009 up to $31 \mathrm{TWh}$ in 2014, rising to almost 6.5 percent of electricity consumption in 2015 . The $\mathrm{CO}_{2}$ impact associated with this ICT usage would rise accordingly from $20 \mathrm{Mt}$ to $25 \mathrm{Mt}$, with a sector-bysector analysis of ICT usage exhibiting a similar decomposition to what was said about worldwide usage: In 2009, 25 percent of electricity consumption was allocated to telecommunication systems, while 62 percent was allocated to office computing (desktop computers, printers, local networks).

However these older projections need to be revisited according to newer and more detailed reports produced by the 2013 European project from the European Network of Excellence in Internet Science (EINS) [6,7], which evaluated the global worldwide ICT sector electricity consumption in 2012 at 920TWh or 4.7 percent of the 19,500 TWh of worldwide electricity consumption. This translates approximately into $530 \mathrm{Mt}$ of $\mathrm{CO}_{2}$, which itself is 1.7 percent of the worldwide total amount. It is important to recall $[8,11]$ that electricity represents 15 percent of worldwide energy production, but is responsible for 37 percent of $\mathrm{CO}_{2}$ emissions. Moreover, Europe's share of electrical energy for ICT amounts to 1.6 percent of the worldwide total [12]. We may also understand better the scope of ICT's energy consumption [6] sector-by- 
sector: Data centers account for a third of the ICT total, while devices account for another third, and telecommunication networks account for the last third. This is also consistent with the fact that data centers consumed approximately 1.5 percent of the total electricity produced in 2012.

We warned earlier that our definition of ICT, which excludes TV and sound systems, could lead to estimates of energy footprint that differ from other published reports. For instance, a report commissioned by the French government in 2008 [11] included television sets, printers and other appliances, which led them to the larger figure of 13 percent for the overall ratio of electricity consumption by ICT. The same report showed data centers in France accounted for less than 1 percent of total electricity consumption.

\section{ICT-related Energy Consumption: The case for moderate growth}

The year 2007 was a high point in public opinion as well as in the written press, as far as concerns about the growth of ICT's energy consumption. It tends to explain why the 2020 figure found in the 2007 Gartner report [9] was so high (3270 TWh versus 920 TWh measured in 2012). Another well-known report from 2010 [13] stated electricity consumption by data centers had risen by 56 percent in five years, a figure that grew much faster than the 36 percent overall increase for U.S. electricity usage during the same period. Using more recent figures, the previously quoted EINS report stated ICT's share in electricity consumption rose from 4 percent in 2007 to 4.7 percent in 2012. Thus recent data shows sustained and regular growth in ICT energy consumption, but nothing like the exponential "explosion" that was feared by some a decade ago.

However, it is worth taking a closer look at the inducers of the growth of ICT energy consumption, since it is true ICT usage is indeed "exploding" and this intense growth is likely to continue for the next decade, as illustrated by forecasts for mobile and fixed data networks. Figure 1 is a schematic representation of a causality chain that goes from ICT needs (usage) down to electricity consumption, illustrating a chain of steps involved in the growth of usage, and annotates each step with energy-saving advances. The overall effect is to limit the growth for ICT energy consumption to "moderate." 
Figure 1. From computing usage to electricity consumption in data centers.

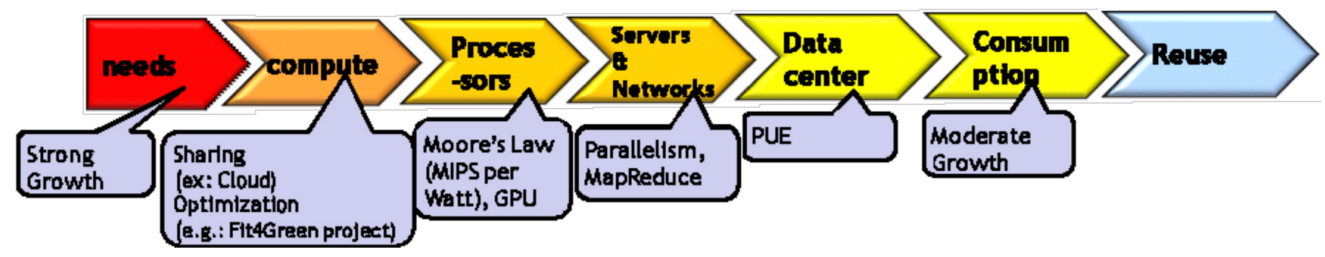

The following comments clarify the energy efficiency gains at each transformation step in leftto-right order of Figure 1:

- The rise of the energy needs of ICT is fed by the increase in power and speed of computers (from handsets to servers), by the constant increase in network bandwidth, and the increasing worldwide population who have access to these services.

- The development of "cloud computing" has a beneficial influence on energy consumption by sharing processors and other hardware, to avoid data centers being grossly underused as in the past. The ongoing research dedicated to energy optimization for computing is providing interesting early results. Note that computers are being put "to sleep" when they are not used, despite the fact that "going to sleep" and "waking up" are often computationally and energy intensive.

- Technological progress also favors energy efficiency because each newer generation of devices is smaller and more energy efficient. New processor architectures are getting more efficient. An example is the use of GPUs (graphical processing units) instead of CPUs (computing processing units) for a number of scientific computing tasks, which are thus processed with better energy efficiency.

- Massive parallelization is a global trend in computing, since the technological progress behind "Moore's law" no longer expresses as faster clock frequencies but rather as the placing of multiple computing cores on a chipset. Although parallelization places a burden on software, since programming has yet to evolve toward massively distributed systems, it does yield far better energy efficiency.

- Data centers are making their own progress as far as energy consumption is concerned. This is measured through the PUE (power usage effectiveness) metric, which is the ratio of consumed energy during the computing process over the total amount of energy consumed for the data center operations (including cooling). This type of optimization is popularized under the name of "Green IT." Thus we have 
seen the PUE go down from two for most data centers to close to one for the most efficient data centers, such as some of those that are run by Google or Facebook.

- It is possible to achieve a PUE ratio that is smaller than one by reuse of otherwise wasted energy. For example, computing systems produce heat proportional to the number of operations, or the number of I/Os, they perform. That heat can be recycled for other uses, such as heating the buildings adjacent to the data center. This is an interesting future approach, and computation may be moved to locations where heat is needed. There are a few examples already that use heat from a data center for local usage.

- Yet another exciting direction would be to couple "intermittent computing" with "intermittent sources of renewable energy" [14, 15].

The above reasoning can apply, to a certain extent, to all kinds of ICT systems ranging from personal devices (smart phones, tablets, laptops) to telecommunication network equipment, since the same silicon technology yields increasingly better performance for each watt of electricity that is used. Indeed, data regarding "Moore's Law" expressed in computations per KWh, also known as "Koomey's Law" [16], indicates computations per KWh have doubled approximately every 1.52 years over the given period.

Smart phones are the most popular terminal equipment. An individual device's energy consumption (from the recharging source) ranges from a few to $10 \mathrm{KWH}$ per year. The one billion devices worldwide, therefore, consume a total $10 \mathrm{TWH}$ per year. We can compare this with the total energy consumption to operate ICT equipment (excluding home entertainment systems), which is on the order of 1,000 TWH per year. Thus our very popular ubiquitous mobile devices add approximately 1 percent to the overall energy usage for ICT.

Our earlier comments about sharing resources also apply to telecommunication networks, where the "cloud" plays a growing role. On the other hand, this sharing principle does not hold for personal devices. On the contrary, the number of personal connected objects per human individual, known as the Internet of Things (IOT) will be constantly growing. The same is true for screens: We own more and more screens, because everyone in the world is gradually becoming multi-equipped. The energy consumption for these screens, measured in $\mathrm{W} / \mathrm{m}^{2}$, is improving rapidly thanks to new display technologies (such as LED and OLED). Energy consumption of screens appears to depend more on the number of screens than on their size. Thus the big unknown into the future remains the effect of the loT itself.

The fact that ICT energy growth in general, and the consumption of electrical energy by the growth of data centers in particular, is more moderate than what was feared in 2007, does not mean that we should not worry about the energy costs of ICT. Energy is a key strategic parameter in the economics of a data center. The price of electricity plays a key role in the strategic decision about where to locate a new data center. In the United States, the cost of electricity has been reduced thanks to the use of non-conventional gas and oil, resulting in data 
center relocations to locations where electricity costs between $\$ 40$ and $\$ 60$ per $\mathrm{MWh}$-those are 40 percent cost reductions with respect to the UK and 70 percent reductions with respect to Germany.

\section{The Energy Balance For and Against ICT}

To evaluate ICT's impact on energy consumption, one should ask two questions:

1. What is ICT's contribution to the creation of value in the production and service industries, and hence how can we assign ICT's use of energy to different industry sectors?

2. What is ICT's contribution to the reduction of energy consumption?

The first question is not addressed in this article. It is the topic of numerous debates; however, it seems clear ICT contributes to a large and growing part of the economy, which may be larger than the 2 percent reported earlier.

The second question is also very important and has been the focus of much debate in recent years. The World Wildlife Forum's (WWF) 2012 report predicted the positive impact of ICT to be $4 \mathrm{Gt}$ (gigatonnes) of $\mathrm{CO}_{2}$ in 2030 [17]. This figure comes from a median scenario; the report quotes a range of scenarios, from a very conservative one with only $1 \mathrm{Gt}$ saved through "smart" technologies, to a very optimistic one at $8 \mathrm{Gt}$ of $\mathrm{CO}_{2}$ savings. To illustrate these findings, the "top five" areas where "smart" technology (with embedded ICT) is claimed to support significant savings are:

- Embedded computing and driving assistance for vehicles and transport optimization (1.5 $\mathrm{Gt}$ ). This is one of the most important; we shall discuss it again later.

- The e-commerce and e-goods (digital products) industry (0.9 Gt).

- The use of ICT in the energy and industrial sectors, for instance for savings in demand (0.8 Gt)

- The use of ICT in existing buildings to optimize energy consumption (0.5 Gt).

- The use of ICT in new buildings (0.4Gt) for overall energy optimization.

In the WWF report, the "smart" domains mentioned include smart cars, smart homes, smart cities, smart grids, etc. [17]. Another study from the Global e-Sustainability Initiative (GeSI), with a broader scope and a shorter time horizon, suggested a more optimistic and aggressive scenario that credits ICT with $9 \mathrm{Gt} \mathrm{CO}_{2}$ reduction in 2020 [18]. The comparison of the two reports requires listing GeSI's sectors: 
- Transportation (1.9 Gt) with a focus on ITS (intelligent transportation systems) development

- $\operatorname{Energy}(2 \mathrm{Gt})$

- Agriculture (1.6 Gt)

- Construction and building (old and new) (1.6 Gt)

- Manufacturing industries (1.3 Gt)

- Services (0.7 Gt).

The GeSI study uses a wider scope to define ICT [18]. As a consequence, the green house gases (GHG) contribution of ICT was evaluated at $0.9 \mathrm{Gt}$ in 2011, with a forecasted growth to $1.3 \mathrm{Gt}$ in 2020 (which is moderate growth in line with the conclusions of the previous section). The $0.9 \mathrm{Gt}$ value (which is significantly higher than the $0.5 \mathrm{Gt}$ value we quoted early on) may be explained by ICT scoping difference that neglects areas such as entertainment. We can derive from these two reports that although there is a wide range of possible futures, the contribution of ICT to GHG reduction could largely offset the GHG emission produced by ICT usage. This is all the more important since public opinion tends to fear ICT's energy consumption fed by alarmist forecasts. Indeed, many news articles have singled out exaggerated claims and created vivid, but inexact, comparisons.

"Second Life," a virtual reality 3D game, was quite popular in the early 2000s. Some said that a Second Life avatar was more costly, energy-wise, than the average African citizen, on par, approximately with a citizen from Brazil. The claim was based on the confusion between the number of avatars (approximately 10 million at that time) and the number of simultaneous players (a few tens of thousands). The poor assumption was that a hypothetical gamer would play all year long from dawn to night and consume as much electricity as a Brazilian inhabitant, while the actual electricity consumption per avatar would have been one thousand times smaller.

Google has been the subject of many claims, somewhat fed by the secrecy surrounding its energy consumption in data centers. Since more data is now available, we can safely estimate that Google's total yearly energy consumption is $2 \mathrm{TWh}$, with a peak power of $260 \mathrm{MW}$, which is roughly the equivalent of 1.3 million servers (200 W per server) [19]. A small part of this electricity consumption (approximately 5 percent) is used for search, which is only one of many Google services such Gmail, YouTube, etc. One search request, typically processed by a thousand or so servers to achieve low latency of less than $200 \mathrm{~ms}$, consumes $0.3 \mathrm{Wh}$. This is equivalent to the consumption of a personal computer during the 10 seconds that it takes to ask the question and read the result. 
Facebook is yet another center of attention, with a global yearly electricity consumption of 0.5 TWh, amounting approximately to $500 \mathrm{Wh}$ per user. If we take the average individual connection time into consideration (around 20 hours per individual user per month, with a rather narrow distribution among countries, Canada being the highest with 40 hours), we obtain an effective power usage of $2 \mathrm{~W}$ during a Facebook session.

\section{Another Look at ICT and its Impact on Transportation}

Much work has been devoted to incorporate ICT into the management of motorway traffic [20], and in addition smart cars may (some day) have an important effect. However an interesting trend in personal transportation has been observed in different recent studies of automobile miles driven in the U.S. [21, 22]. Since 2007 the average number of miles traveled in private automobiles per inhabitant has dropped by approximately 7 percent. This departs from a long U.S. trend of regular increases with a few short dips. There was a significant dip of more than 2 percent, followed by stagnation since 2007, despite the growth in population. Economists argued the sharp rise of gasoline prices caused the curtailment. We speculate ICT also played a role. ICT facilitates the tendencies to work from home and to shop online. Soon people will also be increasingly learning online. Furthermore ICT gives a real advantage to commuting via public transportation, since people can work or communicate from trains and buses, while they have to focus on driving their cars if they travel in individual vehicles. This speculation does not include the probable energy-saving effects of driverless cars.

Most of the "economic recessions" have indeed caused a dip in number of miles driven. However the data show that as soon as recessions end, the growth in driven miles picks up again - with the notable exception of the 2007-2009 recession where the dip lasted for more than five years beyond the recession.

While the impact of the subprime mortgage crisis may have caused this initial dip from 2007 to 2009, in which sharply higher gasoline prices played a role, a hypothesis worthy of analysis is that from 2010 to 2014, for a total of more than five years, ICT could be credited for saving a significant part of the 12 trillion miles of road traffic over four years. The resulting energy savings and $\mathrm{CO}_{2}$ impact reduction (even without the corresponding energy savings in road repairs, car repairs and wear and tear) is huge, since an average published figure of 33 milesper-gallon on average for that period [23] at roughly $2.5 \mathrm{Kg}$ of $\mathrm{CO}_{2}$ per liter of burned fuel, yields 3.435 billion (metric) tons of $\mathrm{CO}_{2}$ emissions that were saved. In terms of a personal computer operating at $100 \mathrm{~W}$ power level (which is on the high side) for six full hours per day (which is also high), or $600 \mathrm{WH}$ per day or a total of $180 \mathrm{KWH}$ for a 300 day working year, at the previously cited world average of $400 \mathrm{~g}$ [10] of $\mathrm{CO}_{2}$ per electric $\mathrm{KWH}$ [10] the $\mathrm{CO}_{2}$ equivalent in ICT's $\mathrm{CO}_{2}$ impact is equivalent to 1.2 billion computers operating over the same four-year period. In simple terms, the savings in individual car travel in the U.S. from 2010 to 2014 is equivalent to the $\mathrm{CO}_{2}$ impact of all the large PCs or small servers in the world. 
It is worth noting after the price of gasoline dropped by more than 25 percent in 2014 the total number of miles travelled in personal vehicles in the U.S. has increased again, by January 2015 reaching the 12-month level that had been previously observed in 2008 . However the average number of miles traveled per individual has remained well below previous data, because the population has grown as well. Here is what an expert says about the correlation between the prices of gasoline and the number of miles travelled: "This population-adjusted version puts us about where we were in November of 1999 ... As is readily apparent, the correlation is fairly weak over the entire timeframe. And, despite the volatility in gasoline prices since the onset of the Great Recession, the correlation since December 2007 has been even weaker. That said, the 2014 decline in gasoline prices has been accompanied by a rise in miles traveled. In the big picture, there are profound behavioral issues apart from gasoline prices that are influencing miles traveled. These would include the demographics of an aging population in which older people drive less, continuing high unemployment, the ever-growing ability to work remote in the era of the Internet and the use of ever-growing communication technologies as a partial substitute for face-to-face interaction" [24].

\section{Conclusions and Future Work}

This paper has taken a broad look at energy consumption of information and communication technologies across the world, as well as the impact of greenhouse emissions. The initial alarmist reports from the mid 2000's regarding the potentially explosive growth of energy consumption by ICT have not been borne out. At the same time, ICT's energy consumption does remain a growing and significant concern both in terms of $\mathrm{CO}_{2}$ emissions and for the economic cost it represents. If we can recover the heat generated by computers and ICT for other useswhich already happens indirectly in the heating of homes and offices and in some pilot environments, while also moving computation to areas where energy originates with renewable resources or where heat can be more easily dissipated without artificial coolingthen the overall energy efficiency of our computer systems and networks can significantly improve. The recent reduction in total miles traveled in private vehicles in the United States (and some other developed countries) cannot be explained by the economic crisis that started around 2007, and it is likely the new modes of work and commerce introduced by ICT have had some impact. In the future we must turn to research to help us better understand these areas. We may be able to dynamically manage system performance in order to achieve the desired quality of service (QoS) from a computer system at the lowest possible energy cost [25] and $\mathrm{CO}_{2}$ impact. The cloud can help us exploit servers that are not just secure and cost effective, but also energy efficient [26] using scheduling schemes that incorporate energy consumption as part of QoS [1]. In packet and other data networks, we may access network paths that provide us with the best energy and QoS trade-offs [27, 28], while future communication systems may use renewable energy from the sun, the wind, the sea, and physical vibrations to offer non-stop service [29]. The manner in which we organize computations can also be optimized substantially in order to reduce energy consumption in processing and cooling, also by 
reclaiming heat [30-32], and through electronic systems that can operate at high temperatures without the need for cooling [4]. A dynamic "on demand" use of energy by computation and communication may also allow us to handle energy networks with the flexibility that we use to access the Internet [33-35]. For the design and control of such integrated energy-computationcommunication networks, we may be able to exploit queuing network-based methods, which have proved to be extremely successful in distributed computer system and telecommunication network design $[2,36]$.

To us the big unknown is the impact that the Internet of Things will have on ICT's energy consumption, while also driving down other uses of energy through greater efficiency and optimization.

Our overall conclusion, however, is ICT energy costs are not runaway and ICT may actually be causing a decline of overall energy usage. All these issues require further research to create the even more energy efficient ICT systems of the future.

\section{About the Authors}

Erol Gelenbe, FACM, FIEEE and FIET (UK), is a Fellow of the National Science Academies of Hungary, Poland and Turkey, the National Academy of Technologies of France, and a Fellow of the Royal Academy of Sciences, Letters and Arts of Belgium. He holds the Dennis Gabor Chair in Electrical and Electronic Engineering at Imperial College, and is currently PI of the EU FP7 NEMESYS Project on Mobile Network Security. His recent work includes Cloud Computing, and energy savings in computer systems and networks. Known for his research on systems performance modeling, his early work led to the QNAP/Modline commercial software for Performance Engineering of Computer Systems. He developed the prototype for FLEXSIM, an object oriented discrete event simulations software for flexible manufacturing systems, designed the SYCOMORE multiprocessor voice-packet switch, the fiber optics random access network XANTHOS, and the first fully implemented Autonomic "Cognitive Packet Network" in 2004. Recipient of the "In Memoriam Dennis Gabor Award" of the Hungarian Academy of Sciences in 2013, the 2010 IET Oliver Lodge Medal in the UK, the 2008 ACM SIGMETRICS LifeTime Achievement Award, the 1996 Grand Prix France Telecom of the French Academy of Sciences and the Parlar Science Foundation Award (Turkey, 1994), he was awarded Knight of the Legion of Honour and Officer of the Order of Merit (France), Grand Officer of the Order of the Star and Commander of Merit of Italy, and Honoris Causa doctorates from the Universities of Liege (Belgium), Rome II (Italy), and Bogazici (Turkey). His recent work appears in the Physical Review, Communications of the ACM, ACM/IEEE Trans. on Bioinformatics, ACM Trans. on Internet Technology, ACM Trans. on Autonomous and Adaptive Systems, IEEE Trans. on NanoBio Systems, Proceedings of the Royal Society, IEEE Transactions on Forensics and Security, IEEE Transactions on Emerging Topics in Computing, and the journal Energies. 
Yves Caseau is Director of the Digital Agency of Groupe AXA, a corporate leader in insurance and financial security, where his role is to accelerate the development of digital products and services for AXA's divisions, especially for mobile terminals, and to foster innovation for AXA's customers. He leads efforts to improve the technological and digital synergies between various ICT services with AXA's ICT teams. Prior to joining AXA, since 2007 he was Vice-CEO of Bouygues Télécom, where he lead the activities regarding new products, services and innovation, with special emphasis on "triple play» products and mobile services. Between 2001 and 2006, he served as Director of Information Systems at Groupe Bouygues and prior to that as Director of New Technologies at Bouygues. From 1994 to 2001 he headed Bouygue's corporate e-lab, which was the corporate R\&D Lab for new technologies and operations analysis and optimization. A graduate of Ecole Normale Supérieure in Paris, with an MBA from the Collège des Ingénieurs, he started his career as a researcher in Software Engineering at the Alcatel Research Laboratory, before working on operations research at Bellcore in the US. A Fellow of the French National Academy of Technologies, he is the current chair of its Committee on Information and Communication Technologies.

\section{References}

[1] Gelenbe, E. Sensible decisions based on QoS. Computational Management Science 1, 1 (2003), 1-14.

[2] Gelenbe, E. The first decade of G-networks. European Journal of Operational Research 126, 2 (2000), 231-232.

[3] Gelenbe, E., Khaled, H., and Kaptan, V. Simulating autonomous agents in augmented reality. Journal of Systems and Software 74, 3 (2005), 255-268.

[4] Fettweis, G. and Zimmermann, E. ICT energy consumption - trends and challenges. The 11th International Symposium on Wireless Personal Multimedia Communications (WPMC 2008), Finnish Lapland, Sep. 8-11, 2008.

[5] Erol-Kantarci, M. and Mouftah, H.T. Energy-efficient information and communication infrastructures in the Smart Grid: A survey on interactions and open issues. Communications Surveys and Tutorials. IEEE. 2014. DOI: 10.1109/COMST.2014.2341600.

[6] The EINS Consortium. Overview of ICT energy consumption (D8.1). Report FP72888021. European Network of Excellence in Internet Science. February 2013. 
[7] Van Heddeghem, W., Lambert, S., Lanoo, B., Colle, D., Pickavet, M., and Demeester, P. Trends in worldwide ICT electricity consumption from 2007 to 2012. Computer Communications 50 (2014), 64-76.

[8] 2012 Key World Energy Statistics. International Energy Agency. 2012.

[9] Gartner, Inc. Gartner Estimates (ICT) Industry Accounts for 2 Percent of Global CO2 Emissions. Gartner. April 26, 2007.

[10] Comparison of Lifecycle GreenHouse Gas Emissions of Various Electricity Generation Sources. Word Nuclear Association. July 2011.

[11] Breuil, H., Burette, D., Flüry-Herard, B., Cueugniet, J., and Vignolles, D. Rapport TIC et Développement Durable. December 2008.

[12] Hilty, L M., Coroama, V., Ossés de Eicker, M., Ruddy, T. F., and Müller, E. The Role of ICT in Energy Consumption and Energy Efficiency. Project FP7-ICT-2007-2, ICT- Ensure. EMPA. 2009.

[13] Koomey, J.G. Growth in Data Center Electricity Use 2005 to 2010. Oakland, CA, Analytics Press. August 1, 2011.

[14] Gelenbe, E. Synchronising energy harvesting and data packets in a wireless sensor. Energies 8, 1 (2015), 356-369.

[15] Gelenbe, E. and Ceran, Elif Tugce. Central or distributed energy storage for processors with energy harvesting. In Proceedings of 4th IFIP Conference on Sustainable Internet and ICT for Sustainability 2015 (SustainIT'15), Madrid, Spain, April 2015.

[16] Koomey, J., Berard, S., Sanchez, M. and Wong, H. Implications of historical trends in the electrical efficiency of computing. Annals of the History of Computing 33, 3 (2011), 46-54. [17] World Wildlife Forum. The potential global $\mathrm{CO}_{2}$ reductions from ICT use. WWF. March 2008.

[18] Global e-Sustainability Initiative (GeSI) and Boston Consulting Group (BCG). GeSI SMARTer 2020: The Role of ICT in Driving a Sustainable Future. December 2012;

[19] Gland, J. Google Details, and Defends, its use of Electricity. New York Times. September 8, 2011. 
[20] Feng, W., and Elmirghani, J.M.H. Green ICT: Energy efficiency in a motorway model. Third International Conference on next generation mobile applications, services and technologies (NGMAST '09). 2009, 389-394.

[21] Alternative Fuel Data Center. Annual Vehicle Miles Traveled in the U. S. U.S. Department of Energy. June 2014.

[22] Spivak, M., and Schoettele, B. Recent Changes in the Age Composition of Drivers in 15 Countries. University of Michigan Transportation Research Center. October 2011.

[23] Table 4-23: Average Fuel Efficiency of U.S. Light Duty Vehicles. National Transportation Statistics. Bureau of Transportation Statistics. United States Department of Transportation. 2015.

[24] Short, D. Vehicle Miles Traveled: A New Look at Our Evolving Behavior. May 21, 2015.

[25] Gelenbe, E., and Lent, R. Trade-offs between energy and quality of service Sustain/T 2012 (Pisa, Italy). IEEE, 2012, 1-5.

[26] Gelenbe, E., and Lent, R. Energy-QoS Trade-Offs in mobile service selection. Future Internet 5, 2 (2013), 128-139.

[27] Sakellari, G., Morfopoulou, C., Mahmoodi, T., and Gelenbe, E. Using energy criteria to admit flows in a wired network. ISCIS 2012 (Paris). Spinger, 2013, 63-72,

[28] Gelenbe, E., and Morfopoulou, C. A Framework for Energy-Aware Routing in Packet Networks. Comput. J. 54, 6 (2011), 850-859.

[29] Gelenbe, E., Gündüz, D., Kulah, H., and Uysal-Biyikoglu, E. Energy Harvesting Communication Networks: Optimization and Demonstration - The E-CROPS Project. 24th TIWDC 2013 "Green ICT." IEEEXplore. Sept. 23 - 25, 2013, Genoa, Italy.

[30] Aupy, G., Benoit, A., Dufossé, F., and Robert, Y. Reclaiming the energy of a schedule: models and algorithms. Concurrency and Computation: Practice and Experience 25, 11 (2013), 1505-1523.

[31] Diouri, M., Tsafack Chetsa, G., Glück, O., Lefevre, L., Pierson, J.-L., Stolf, P., and Da Costa, G. Energy efficiency in HPC with and without knowledge on applications and services. International Journal of High Performance Computing Applications. 27 (2013), 232-243. 
[32] Orgerie, A.-C., Dias de Assunção, M., and Lefèvre, L. A Survey on Techniques for Improving the Energy Efficiency of Large Scale Distributed Systems. ACM Computing Surveys 46, 4 (2014).

[33] Gelenbe, E. Energy packet networks: smart electricity storage to meet surges in demand. In Proceedings of the 5th International ICST Conference on Simulation Tools and Techniques (SimuTools 2012). ICST, Brussels, Belgium, 2012,1-7.

[34] Sakai, K., and Okabe, Y. Quality-aware energy routing toward on-demand home energy networking. In Proceedings of 2011 IEEE Consumer Communications and Network Conference (Las Vegas, 9-12 Jan.) IEEE, 2011, 1041-1044.

[35] Takahashi, R., Takuno, T., and Hikihara, T. Estimation of power packet transfer properties on indoor Power Line channel. Energies 5, 7 (2012) 2141-2149;.doi:10.3390/en5072141

[36] Gelenbe, E., and Fourneau, J.-M. Random neural networks with multiple classes of signals. Neural Computation 11, 4 (1999), 953-963.

DOI: $10.1145 / 2755977$ 